Article

\title{
Heat Transfer Enhancement of Falling Film Evaporation on a Horizontal Tube by Thermal Spray Coating
}

\author{
Tsutomu Ubara, Hitoshi Asano *(D) and Katsumi Sugimoto \\ Department of Mechanical Engineering, Graduate School of Engineering, Kobe University, Kobe 657-8501, Japan; \\ 195t310t@stu.kobe-u.ac.jp (T.U.); sugimoto@mech.kobe-u.ac.jp (K.S.) \\ * Correspondence: asano@mech.kobe-u.ac.jp; Tel.: +81-78-803-6122
}

Received: 8 January 2020; Accepted: 25 February 2020; Published: 29 February 2020

check for updates

\begin{abstract}
Falling film evaporators are gaining popularity as substitutes to typical flooded evaporators because of their low refrigerant charge. It is important to form and keep a thin liquid film on the heat transfer surface to ensure their high heat transfer performance. In this study, as a heat transfer enhancement surface, a fine porous surface processed using thermal spray coating was applied to a smooth copper tube with an outer diameter of $19.05 \mathrm{~mm}$. Heat transfer coefficients of falling film evaporation on a single horizontal tube were experimentally evaluated using the HFC-134a refrigerant. The experiments were performed at a saturation temperature of $20^{\circ} \mathrm{C}$ with the heat flux ranging from 10 to $85 \mathrm{~kW} \cdot \mathrm{m}^{-2}$ and for film Reynolds numbers up to 673 . The study aimed to clarify the effect of the coating on the heat transfer characteristics of falling film evaporation. The results revealed that the coating could suppress partial dry out and enhance nucleate boiling in the falling film. The maximum heat transfer enhancement factor was 5.2 in the experimental range. It was further noted that the effect of the coating was especially strong under a low heat flux condition.
\end{abstract}

Keywords: falling film evaporation; thermal spray coating; heat transfer enhancement; horizontal tube; nucleate boiling

\section{Introduction}

Recently, the charge amount of refrigerant is required to be reduced because the most widely used refrigerants have a high global warming potential (GWP). As a result, falling film evaporators are expected to act as substitutes for flooded heat exchangers. One important issue in improving the heat transfer performance of falling film evaporation is to keep a liquid film on the heat transfer tubes because dry out significantly deteriorates heat transfer [1]. A higher liquid circulation flow rate can improve the wall wetting condition. However, a thicker liquid film leads to higher heat resistance and wall superheat, which further results in nucleate boiling in the liquid film. When nucleate boiling occurs in the liquid film, vapor bubbles can cause liquid entrainment from the surface, leading to a decrease in the liquid film flow rate. If these entrained droplets flow into a compressor, they can cause erosion and deteriorate the adiabatic efficiency. The same problem exists in a binary power generation system that uses a geothermal source of waste heat. In refrigeration systems, machined tubes are usually used in the evaporator. However, in geothermal applications, because corrosion-resistant tubes, such as stainless steel and Inconel tubes, are used in the evaporator, it is difficult to apply a machining process. Therefore, other methods are required for heat transfer enhancement.

Ribatski and Thome [2] investigated the heat transfer in falling film evaporation using HFC-134a on a smooth horizontal tube. The flow condition criteria for dry out occurrence were measured, and a correlative equation was developed considering dry out as an area fraction. Christians and Thome [3] 
evaluated the falling film evaporation and pool boiling heat transfer coefficients of HFC-134a and HFC-236fa at a saturation temperature of $5{ }^{\circ} \mathrm{C}$ for two mechanically processed boiling heat transfer enhanced tubes, Turbo-B5 by Wolverine and Gewa-B5 by Wieland. The film Reynolds numbers were varied from 0 to 3000 , and the heat flux was varied from 35 to $95 \mathrm{~kW} \cdot \mathrm{m}^{-2}$. It was observed that the heat transfer coefficient slightly decreased with increasing heat flux. To prevent partial dry out, Chang and Chiou [4] developed a heat transfer tube bundle with liquid collectors and compared its heat transfer performance with pool boiling results using HCFC-141b. A liquid collector is a half tube that covers the bottom half of the heat transfer surface. Their study revealed that falling film evaporation on the tubes with the liquid collectors produced a higher heat transfer coefficient than those in pool boiling; further, the coefficient decreased without the collector because of partial dry out. Chien and Tsai [5] investigated the effect of a mesh covering a low-finned tube on pool boiling and film evaporation heat transfer using HFC-245fa and HFC-134a as working fluids. For this experiment, 60 fins per inch tube were used, which had a fin thickness of $0.21 \mathrm{~mm}$ and a fin height of $0.4 \mathrm{~mm}$. The mesh had $100 \mathrm{mesh}$ per inch with a wire thickness of $0.09 \mathrm{~mm}$. For HFC-245fa, the tube with the mesh produced a higher heat transfer coefficient than the tube without the mesh, while the opposite results were obtained for HFC-134a. Their study also reported that the effect of the mesh cover depended on the physical properties of the working fluids because the difference in the specific volume of vapor affected the bubble behavior under the mesh. Zheng et al. [6] investigated the effect of wettability of the heat transfer surface on falling film evaporation heat transfer. A super-hydrophilic surface processed by chemical etching was tested using water as the working fluid. Although the heat transfer coefficient was highest for the super-hydrophilic surface at a low liquid flow rate, it was only slightly different from that obtained for a smooth tube with a high liquid flow rate. As water, which has a higher surface tension, was used, the effect of nucleate boiling might be negligible in this case.

In a non-dry out condition, the effect of the flow rate becomes negligible, and that of nucleate boiling heat transfer becomes dominant, as reported by Ribatski and Thome [2], Zhao et al. [7], and Jige et al. [8]. Therefore, nucleate boiling in the liquid film can be effective for heat transfer enhancement. An increase in the nucleation site density and a higher wettability can lead to enhanced nucleate boiling heat transfer with small vapor bubbles. Furthermore, the entrainment of liquid droplets can be suppressed when generated bubbles are small. McHale and Garimella [9] observed boiling bubbles on glass plates with different surface roughnesses, heated by an indium tin oxide (ITO) layer on the surface. FC-72 at a saturation temperature of $57^{\circ} \mathrm{C}$ was used as the working fluid, and the heat flux was varied from 0 to $400 \mathrm{~kW} \cdot \mathrm{m}^{-2}$. The results showed that a rough surface produced a higher nucleation site density and that the boiling bubbles were small. Bock et al. [10] experimentally investigated the effect of surface roughness on the heat transfer characteristics of falling film evaporation using HFC-134a as the working fluid. The arithmetic average surface roughness of the heat transfer surface polished by sandpaper was between 0.1 and $1.9 \mu \mathrm{m}$. It was found that the heat transfer coefficient was improved by the surface roughness in falling film evaporation, as well as in pool boiling. However, the enhancement factor was higher for falling film evaporation. In our study, a rough and thin porous structure processed by a thermal spray coating was applied to the heat transfer surface. Previously, thermal spray coatings had been applied only to pool boiling. Tehver et al. [11] conducted their pool boiling experiments on a porous plasma-sprayed surface and reported that the heating procedure caused a large hysteresis effect on the heat transfer coefficient. Asano et al. [12] evaluated the pool boiling heat transfer coefficients of HCFC-123 at a saturation temperature of $30^{\circ} \mathrm{C}$ on copper tubes with thermal spray coatings of copper. Two types of thermal spraying methods, namely, wire flame spraying and vacuum plasma spraying, were applied. They reported that the heat transfer coefficient was improved by the thermal spray coatings. An enhancement factor of six was obtained by vacuum plasma spraying and was kept for heat flux up to the critical heat flux. Dewangan et al. [13] evaluated the pool boiling heat transfer coefficients for R-134a and R600a on flame sprayed coated tubes with copper powder. Here, the heat flux was varied from 5 to $50 \mathrm{~kW} \cdot \mathrm{m}^{-2}$ at a saturation temperature of $10^{\circ} \mathrm{C}$. They reported that the heat transfer coefficient increased with increasing heat flux, and an enhancement factor of 2.1 was obtained 
by the thermal spray coating. For falling film evaporation, Bogan and Park [14] investigated the effect of a porous surface structure. An $800 \mu \mathrm{m}$ thick porous layer comprised of copper particles with a mean diameter of $75 \mu \mathrm{m}$ was sintered to the outer surface of a plain copper tube with an outer diameter of $15.88 \mathrm{~mm}$. Distilled water at a saturation temperature of $60^{\circ} \mathrm{C}$ was used as the working fluid, and both the sensible and evaporation heat transfers were evaluated. The results indicated that the evaporation heat transfer was higher on the porous tube, while sensible heat transfer was almost the same. Other than this, several studies on the porous structure surface, as a falling film heat transfer enhancement technique, have been conducted [15]. However, most of these studies are on water vaporization, and only a few reports have investigated the application of falling film evaporation in fluorocarbons, where nucleate boiling occurs more actively than in water.

This study aimed to improve falling film evaporation heat transfer by a thermal spray coating. The outside of the tube was arc sprayed with copper. Heat transfer coefficients on the thermal spray coated tube were compared with those on the smooth tube. To evaluate nucleate boiling heat transfer characteristics, pool boiling experiments were also conducted using the same tubes.

\section{Experimental Apparatus and Methods}

\subsection{Experimental Apparatus}

A schematic of the experimental apparatus is shown in Figure 1. The apparatus consisted of a pressure vessel, a refrigerant circulation loop, and a condenser. The tested tube was placed horizontally in the pressure vessel. The pressure vessel was first well evacuated and then filled with the working fluid. Falling film evaporation and pool boiling experiments could be carried out in a pressure vessel by changing the liquid level. In the falling film experiment, the liquid level was set to below the test section. The refrigerant liquid was circulated by a gear pump and supplied to three needle nozzles with an inner diameter of $1.48 \mathrm{~mm}$. The nozzles were fixed at the bottom of a horizontal copper tube above the test tube. As the flow resistance through the nozzles was sufficiently high enough, a uniform distribution could be obtained. The mass flow rate was controlled by the rotational speed of the gear pump and the valve opening in the bypass line and was measured by a Coriolis mass flow meter. The inlet temperature was maintained by a sub-cooler. To supply liquid to the test tube with an axially homogeneous distribution, liquid from the nozzles was supplied via a dummy tube. The dummy tube was a boiling heat transfer enhancement tube with a mechanically processed surface (GEWA-B5H produced by Wieland). After flowing down from the surface of the dummy tube, the liquid spread well in the axial direction and then flowed to the test section immediately below the dummy tube. The gap between the dummy tube and the test tube was set $1 \mathrm{~mm}$ to form a stable liquid film. Both tubes were carefully placed in a horizontal position to prevent maldistribution caused by gravity. The refrigerant temperature was measured by K-type thermocouples at the inlet of the nozzles and placed $65 \mathrm{~mm}$ above and $35 \mathrm{~mm}$ below the test section in the pressure vessel. The refrigerant vapor was condensed in a double tube heat exchanger connected to the upper part of the pressure vessel, and the condensed liquid returned to the test section owing to gravity. The vapor pressure was maintained by the temperature and flow rate of the cooling water and was measured by silicon on sapphire (SOS) pressure transducer in the condensing loop. In the pool boiling experiments, the nozzles and the dummy tube were removed, and the test section was submerged into the liquid pool. 


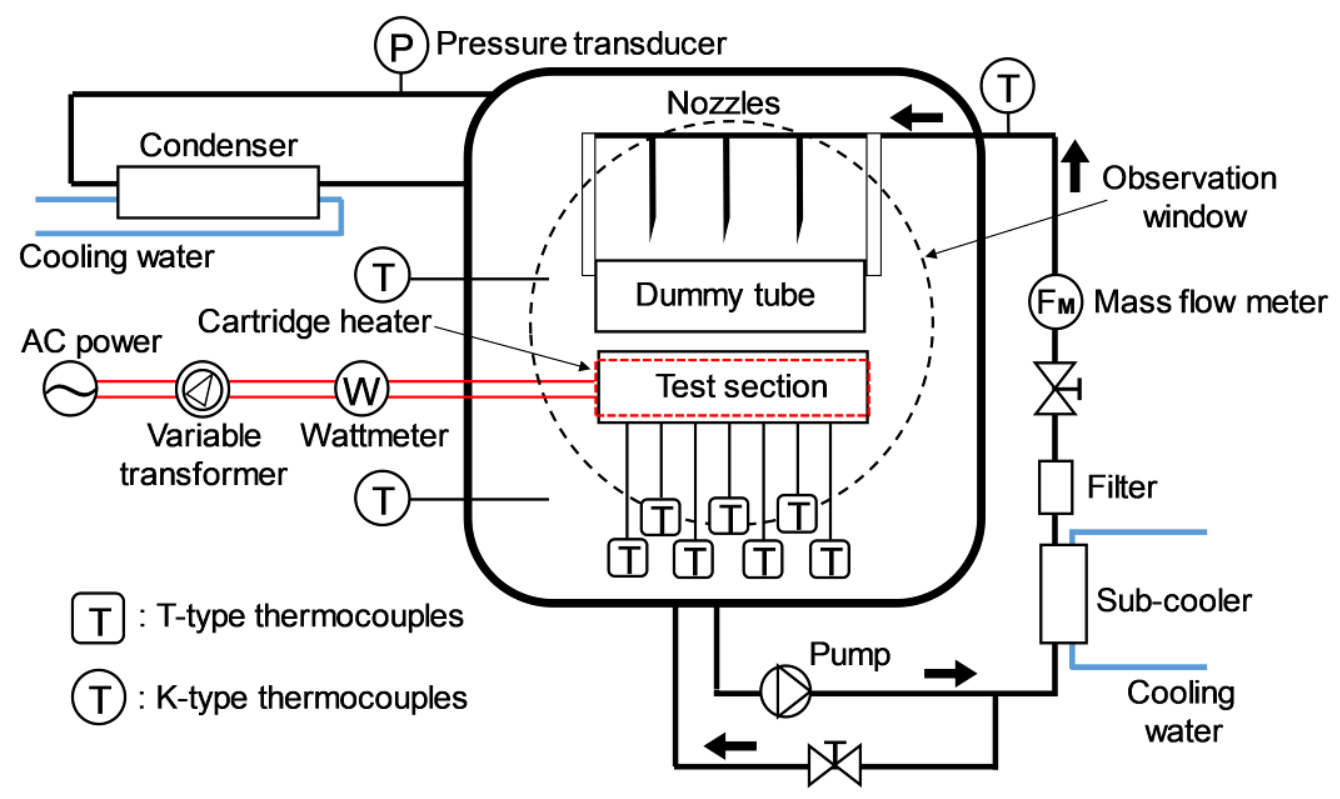

Figure 1. Schematic of the experimental apparatus.

\subsection{Tested Tubes}

Details of the test section are shown in Figure 2. The test section was a copper tube with an outer diameter of $19.05 \mathrm{~mm}$ and a length of $50 \mathrm{~mm}$; it was heated by a cartridge heater inserted along the center axis. The heating length of the heater was equal to that of the test section, and the input power was measured by a wattmeter. The outer wall temperature of the test tube was measured by T-type thermocouples placed at the bottom, to avoid disturbances to the falling liquid film. A constantan wire with a diameter of $0.1 \mathrm{~mm}$ was soldered on the surface of the tube at each measurement point.

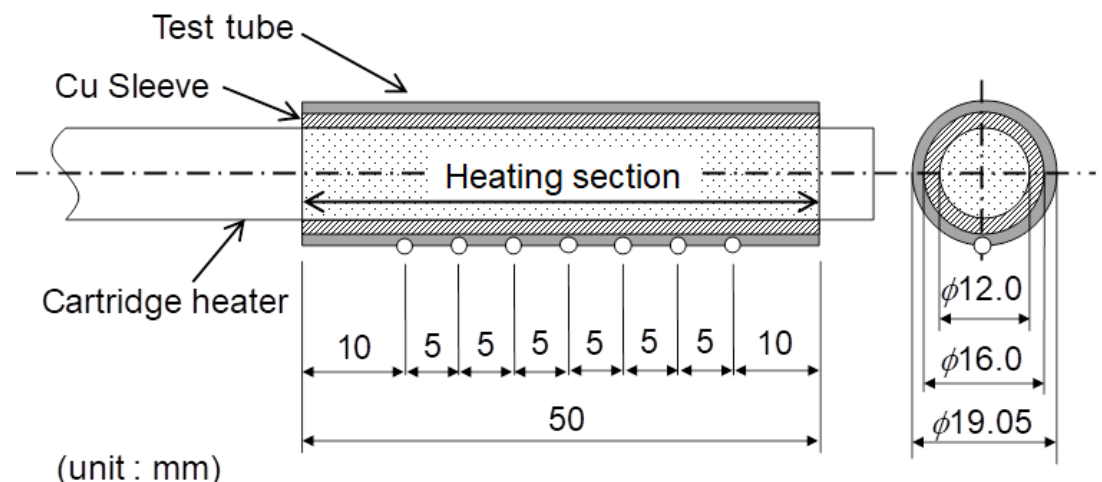

$\circ:$ Temperature measure points

Figure 2. Details of the test section.

In this study, a thermal spray coating was applied to the heat transfer surface for heat transfer enhancement. First, the surface of the test tube was sandblasted, and then melted copper was sprayed. Microphotographs of the thermal spray coating are shown in Figure 3. The coating was formed using an arc wire spraying method in the open air. The top view showed the rough surface formed by the sprayed molten drops. The average surface roughness measured by a laser microscope was $20.6 \mu \mathrm{m}$. In the cross-sectional view, the bright orange area was the base material, and the brown area on the base material was the coating layer. Microscale cavities were observed on the inner and outer surfaces of the coating. 


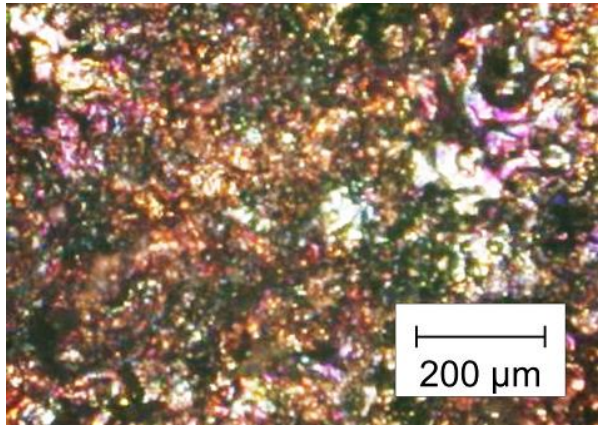

(a)

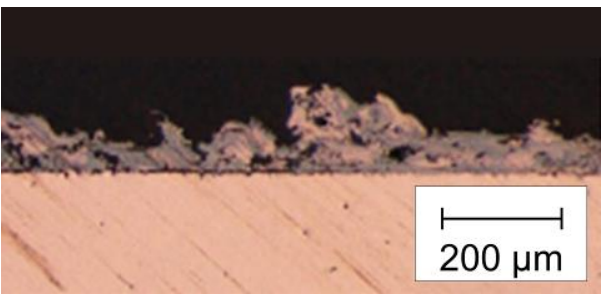

(b)

Figure 3. Microphotographs of the thermal spray coating. (a) Top view. (b) Cross-sectional view.

The heat transfer coefficient was measured using HFC-134a as the working fluid at a saturation temperature of $20^{\circ} \mathrm{C}$ with a set pressure of $0.57 \mathrm{MPa}$. The film Reynolds number was varied from 214 to 673 , and the heat flux was varied from 15 to $85 \mathrm{~kW} \cdot \mathrm{m}^{-2}$. The subcooling degree was maintained within $0.5 \mathrm{~K}$ for the falling film evaporation experiments. The evaporation and boiling behavior on the test section was observed from the horizontal direction during the experiments.

\subsection{Data Reduction}

The film Reynolds number, $R e_{f}$, is defined by

$$
R e_{f}=4 \Gamma \mu_{L}^{-1}=4 m(2 L)^{-1} \mu_{L}^{-1}
$$

where $\Gamma$ is the liquid mass flow rate on the one side per unit length of the test tube $\left(\mathrm{kg} \cdot \mathrm{m}^{-1} \cdot \mathrm{s}^{-1}\right), \mu_{L}$ is the viscosity of the refrigerant liquid (Pa.s), $m$ is the mass flow rate $\left(\mathrm{kg} \cdot \mathrm{s}^{-1}\right)$, and $L$ is the heating length (m). The heat flux $q\left(\mathrm{~W} \cdot \mathrm{m}^{-2}\right)$ is defined by

$$
q=Q A^{-1}=Q(\pi D L)^{-1}
$$

where $Q$ is the heat input $(\mathrm{W}), A$ is the heat transfer area $\left(\mathrm{m}^{2}\right)$, and $D$ is the outer diameter of the test tube $(\mathrm{m})$. For the tube with the thermal spray coating, the heat flux was defined using the diameter at the bottom of the coating. The heat transfer coefficient $\alpha\left(\mathrm{W} \cdot \mathrm{m}^{-2} \cdot \mathrm{K}^{-1}\right)$ is defined by

$$
\alpha=q\left(T_{\text {wall }}-T_{\text {sat }}\right)^{-1}
$$

where $T_{\text {wall }}$ is the measured surface temperature of the test tube $\left({ }^{\circ} \mathrm{C}\right)$, and $T_{\text {sat }}$ is the saturation temperature $\left({ }^{\circ} \mathrm{C}\right)$ calculated from the measured pressure using REFPLOP [16] version 10.0. $T_{\text {wall }}$ is obtained by the trimmed average of the seven measured wall temperatures; the maximum and the minimum values were trimmed, and the others were averaged. Because only five measurements were used for averaging, the error bars represent the maximum and minimum values. The measurement repeatability was confirmed by introducing the trimmed average.

The uncertainties of measurement accuracies are summarized in Table 1.

Table 1. Measurement accuracies.

\begin{tabular}{cc}
\hline Measured Physical Value & Uncertainty \\
\hline Temperature & $\pm 0.05 \mathrm{~K}$ \\
Pressure & $\pm 4 \times 10^{3} \mathrm{~Pa}$ \\
Mass flow rate & $\pm 4 \%$ R.D. \\
Heat input & $\pm 5.5 \mathrm{~W}$ \\
\hline
\end{tabular}




\section{Experimental Results and Discussion}

\subsection{Effect of Liquid Flow rate on Falling Film Evaporation}

Figure 4 shows the heat transfer coefficients of the falling film evaporation against the film Reynolds number, $R e_{f}$. The experimental results of Ribatski and Thome [2] for a smooth tube at a heat flux of $47 \mathrm{~kW} \cdot \mathrm{m}^{-2}$ were also plotted for reference. For the smooth tube, the heat transfer coefficient was improved by increasing the $R e_{f}$ because a higher liquid flow rate led to an increase in the wetted area. The increasing gradient became larger with increasing heat flux. The deterioration in the heat transfer coefficient at a lower $R e_{f}$ was caused by the formation of dry patches on the surface. Refrigerant flow behaviors on the smooth test tube are shown in Figure 5a-c. It was confirmed from the images that the liquid refrigerant flowed from the dummy tube to the test tube as a uniform and continuous liquid film. It could be also seen in Figure 5 a that the entire heat transfer surface was covered by a falling film under the no heating condition with the $R e_{f}$ of 323 . Figure $5 b, c$ show the falling film evaporation behaviors with a heat flux of $33.4 \mathrm{~kW} \cdot \mathrm{m}^{-2}$ for $R e_{f}$ values of 430 and 643 , respectively. A thicker liquid film led to larger heat resistance and a higher wall superheat. When the wall superheat became higher than that at the onset of nucleate boiling, nucleate boiling occurred in the liquid film. Liquid entrainment might increase with the detachment of vapor bubbles and subsequently cause a decrease in the liquid film flow rate. In Figure 5b,c, the nucleate boiling in the liquid film and dry patches were observed. The dry patch areas became smaller with increasing $R e_{f}$. Because a higher heat flux led to higher bubble site density, the improvement in heat transfer by increasing the $R e_{f}$ was greater under the high heat flux condition. In contrast, for the heat flux of $16.7 \mathrm{~kW} \cdot \mathrm{m}^{-2}$, the effect of $R e_{f}$ was smaller because of the smaller effect of nucleate boiling. Compared with the results of a previous study by Ribatski and Thome [2], the results in this study at a heat flux of $50.1 \mathrm{~kW} \cdot \mathrm{m}^{-2}$ took almost the same values, especially at high $R e_{f}$ values over 500. Furthermore, although this study did not cover high flow rate conditions, it could be said that the heat transfer coefficient saturated in the range of $R e_{f}$ values over 1000.

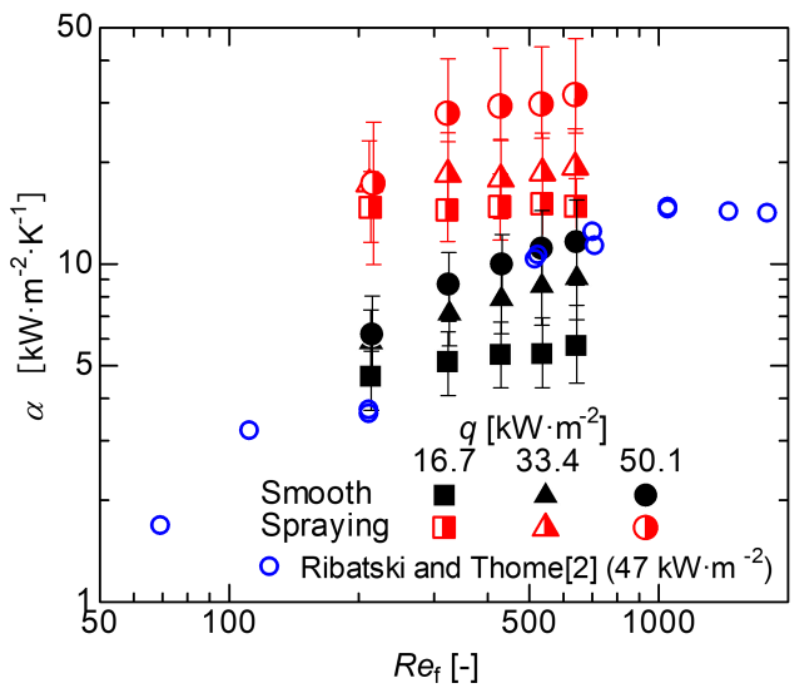

Figure 4. Heat transfer coefficients of falling film evaporation against the film Reynold's number, $R e_{f}$. 

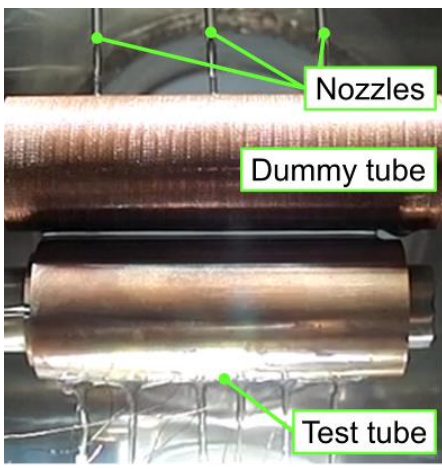

(a)
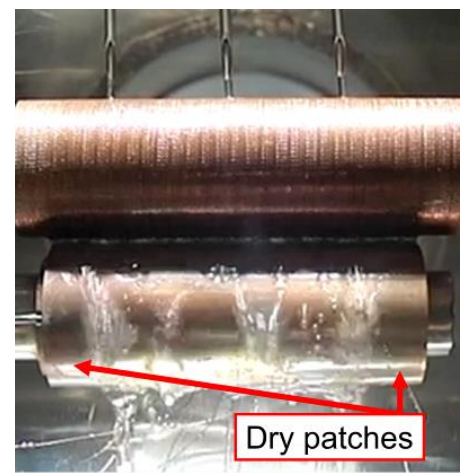

(b)
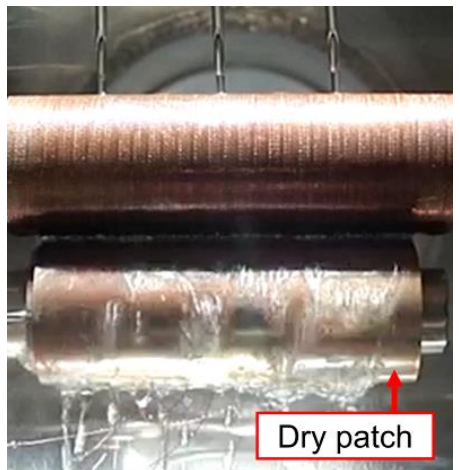

(c)

Figure 5. Falling film evaporation behaviors on the smooth tube. (a) $\operatorname{Re}_{f}=323$ without heating. (b) $R e_{f}=430, q=33.4 \mathrm{~kW} \cdot \mathrm{m}^{-2}$. (c) $R e_{f}=643, q=33.4 \mathrm{~kW} \cdot \mathrm{m}^{-2}$.

Heat transfer enhancement was clearly observed for the thermal spray coated tube. The heat transfer coefficients appeared to saturate for high $R e_{f}$ values over 323 . This tendency was clearly observed at a heat flux of $50.1 \mathrm{~kW} \cdot \mathrm{m}^{-2}$, where the heat transfer coefficient drastically increased with increasing $R e_{f}$ up to 323 but became almost constant with $R e_{f}$ values over 323 . The $R e_{f}$ value for saturation was lower than that in the smooth tube. Additionally, deterioration in the heat transfer coefficient at a lower $R e_{f}$ was not observed for a heat flux of 16.7 and $33.4 \mathrm{~kW} \cdot \mathrm{m}^{-2}$ because here, the heat transfer surface was wetted, and no dry patches were observed. Figure 6 shows the evaporation behavior on the coated tube. The entire heat transfer surface of the coated tube was completely covered by the liquid film under the no-heating condition. Under the heating condition, dry patches were not observed, while nucleate boiling occurred in the liquid film, as shown in Figure 6b,c. The thermal spray coating surface had better wickability. Therefore, the liquid refrigerant spread well, preventing partial dry out. As nucleate boiling heat transfer on the coating was probably dominant compared to forced convection in the experimental conditions, deterioration in the heat transfer coefficient with decreasing $R e_{f}$ was suppressed.

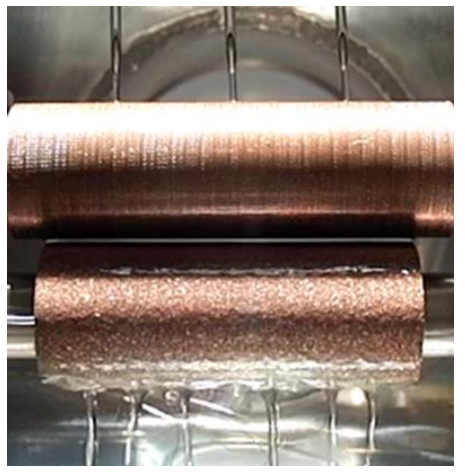

(a)
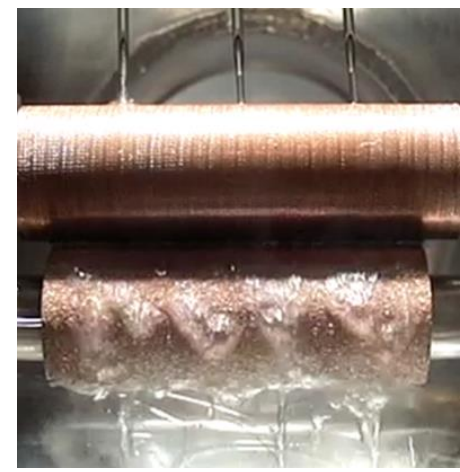

(b)
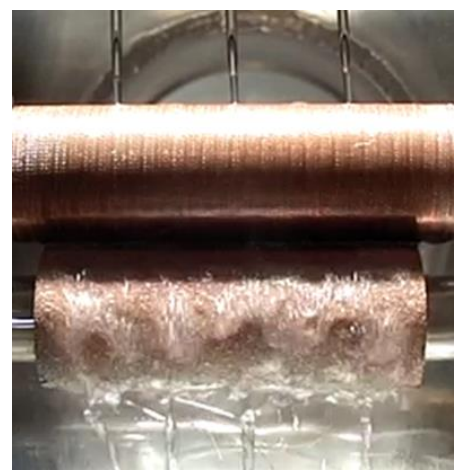

(c)

Figure 6. Falling film evaporation behaviors on the thermal spray coated tube. (a) $R e_{f}=323$ without heating. (b) $R e_{f}=430, q=33.4 \mathrm{~kW} \cdot \mathrm{m}^{-2}$. (c) $R e_{f}=643, q=33.4 \mathrm{~kW} \cdot \mathrm{m}^{-2}$.

\subsection{Effect of Heating Conditions on Falling Film Evaporation}

Figure 7 shows falling film evaporation heat transfer coefficients against the heat flux for the highest $\operatorname{Re}_{f}(643)$ in this experimental range. Because there is a hysteresis effect in the heating procedure of nucleate boiling heat transfer owing to a delay in nucleation activation, measurements were conducted while increasing and decreasing the heat flux. Open and bold symbols show experimental results in the increasing and decreasing processes of the heat flux, respectively. The dashed line shows the correlation of pool boiling heat transfer around a smooth horizontal tube suggested by Cooper [17]. 
For the smooth tube, heat transfer coefficients increased with increasing the heat flux, and the values were slightly lower than the correlation. The gradient was almost the same as the correlation in the heat flux range under $40 \mathrm{~kW} \cdot \mathrm{m}^{-2}$; however, it became smaller over $40 \mathrm{~kW} \cdot \mathrm{m}^{-2}$. The agreement with the gradient indicated that nucleate boiling heat transfer was dominant in this heat flux range. Deterioration in the heat transfer coefficient in the high heat flux range was caused by partial dry out on the surface. Although the results in the decreasing process were lower than those in the increasing process, the difference was minor. This might be attributed to the increase in liquid entrainment, owing to the increase in the activated nucleation site density.

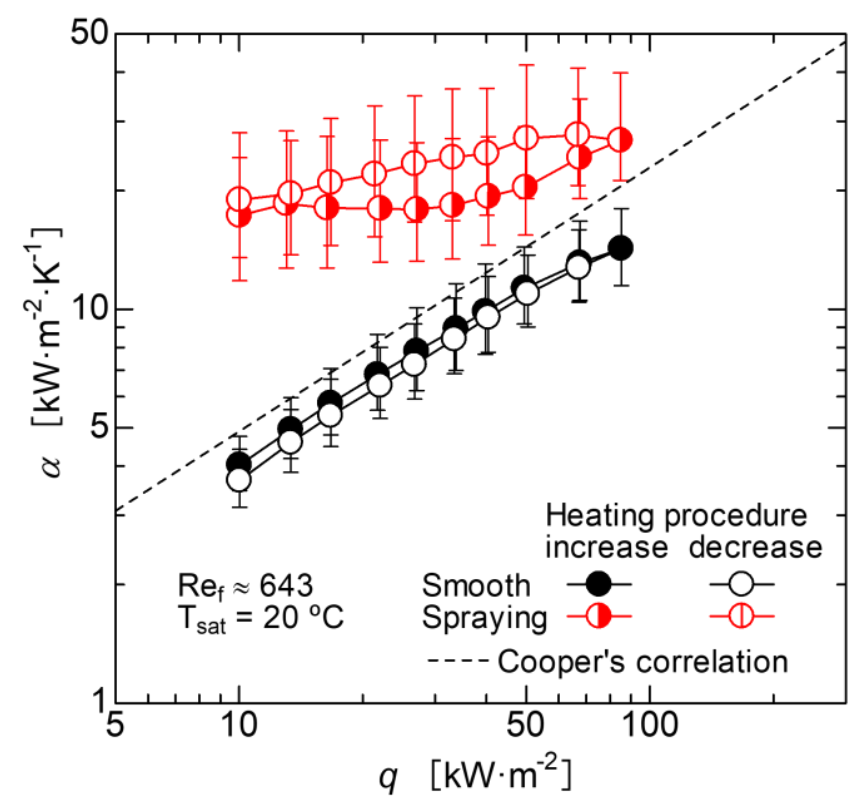

Figure 7. Falling film evaporation heat transfer coefficients on smooth and sprayed coated tubes.

For the thermal spray coated tube, the heat transfer coefficients were almost constant in the increasing process under $33.1 \mathrm{~kW} \cdot \mathrm{m}^{-2}$, and then gradually increased with increasing heat flux over $33.1 \mathrm{~kW} \cdot \mathrm{m}^{-2}$. This indicated that the nucleation site density on the coating must be relatively high under a low heat flux condition. In the heat flux decreasing process, heat transfer coefficients became slightly higher than those in the increasing process and gradually decreased with decreasing heat flux. The improvement in heat transfer in the decreasing process was observed only on the coating tube with the porous surface. This difference was probably caused by the hysteresis effect of the heating procedure. Here, the heat transfer enhancement by the coating could be obtained over the heat flux range and was especially large for lower heat flux values. In this experiment, a maximum enhancement factor of 5.2 was obtained at a heat flux of $10 \mathrm{~kW} \cdot \mathrm{m}^{-2}$ during the decreasing process.

\subsection{Pool Boiling Heat Transfer Characteristics}

Heat transfer coefficients of pool boiling for the smooth and thermal spray-coated surfaces are shown with those of falling film evaporation in Figures 8 and 9, respectively. For the smooth tube (Figure 8), the values for pool boiling were slightly higher than those for falling film evaporation and agreed well with Cooper's correlation. Because partial dry out by liquid entrainment and evaporation did not occur in pool boiling, the increase in the gradient with heat flux was constant even at high heat flux. Other than partial dry out, the cause of deterioration in the heat transfer coefficients for falling film evaporation might be suppression of nucleate boiling in the liquid film. Evaporation from the liquid-vapor surface cooled down the superheated liquid layer. In the pool boiling experiment, no difference was observed between the heat flux increasing and decreasing processes. 


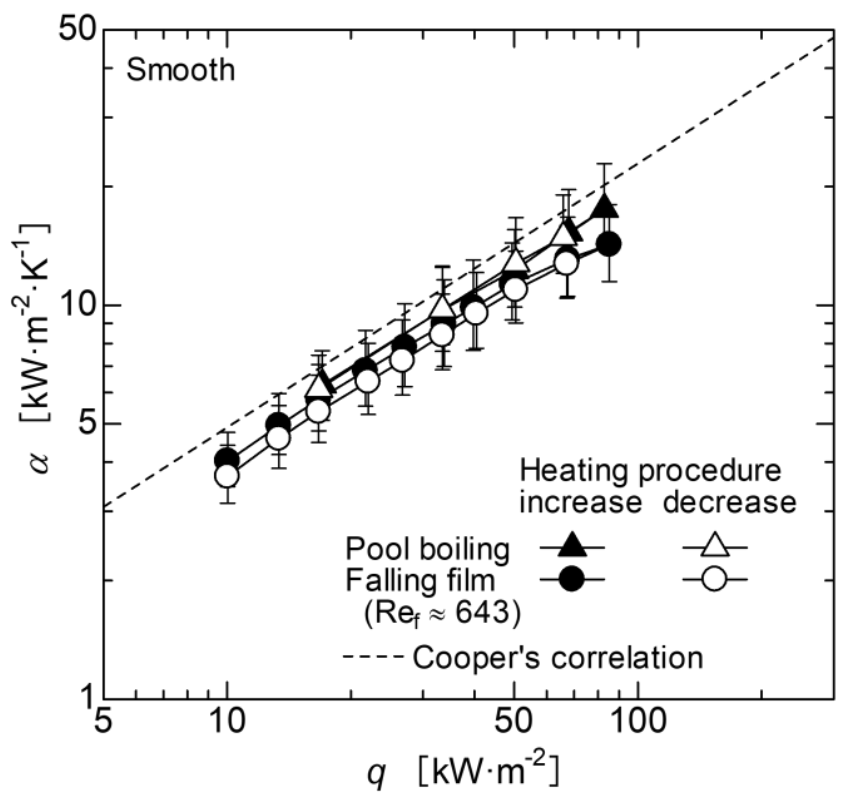

Figure 8. Pool boiling heat transfer coefficients in comparison with those for falling film evaporation on the smooth tube.

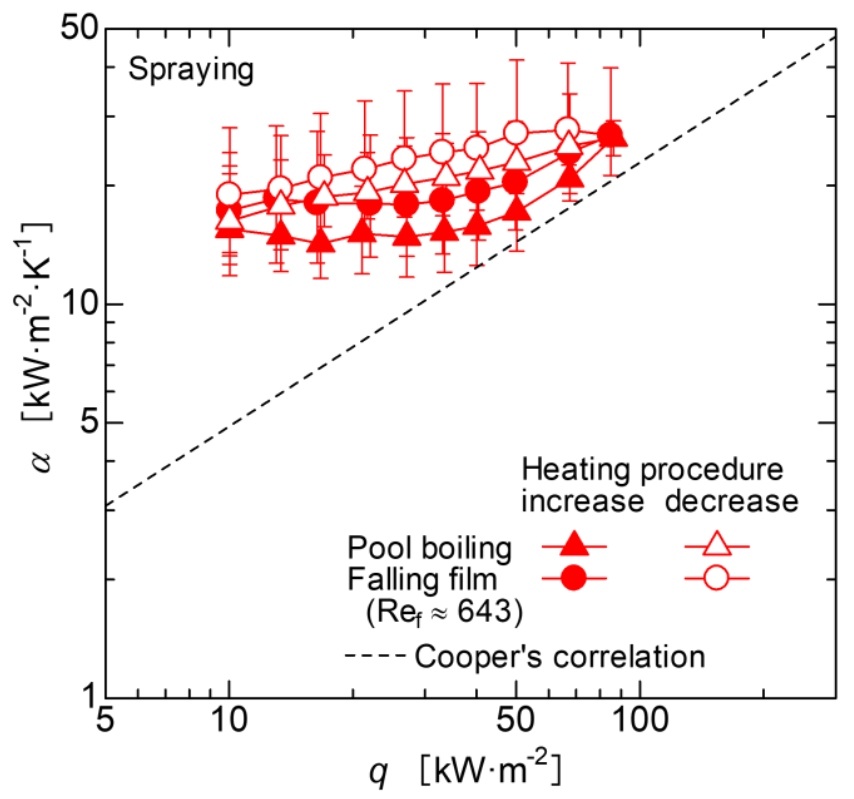

Figure 9. Pool boiling heat transfer coefficients in comparison with those for falling film evaporation on the thermal spray coated tube.

For the thermal spray coated tube (Figure 9), the trend of the thermal coefficients in relation to the heat flux for pool boiling was almost the same as that for falling film evaporation. Although the local heat transfer just on the heat transfer surface was dominant over nucleate boiling, the values were higher for falling film evaporation than pool boiling, which was contrary to the results for the smooth surface. Because the coated tube produced a large bubble site density, leading to a higher heat transfer coefficient, it was believed that a greater number of tiny bubbles were generated and detached from the liquid film. This bubble behavior enhanced evaporation on the liquid film surface. As the wall superheat at the onset of nucleate boiling was quite low for the coated surface, the deterioration effect of nucleate boiling heat transfer due to the decrease in the liquid temperature by evaporation from the liquid film surface as seen for the smooth tube was not observed. In contrast, the hysteresis 
effect due to the delay in bubble site activation was observed not only in pool boiling but also in falling film evaporation.

\section{Conclusions}

Falling film evaporation of HFC-134a on a horizontal tube was experimentally evaluated. Two copper tubes with different surface conditions, a smooth surface and an arc-wire thermal spray coated surface using copper as the coated material, were used as the test tubes. Moreover, the obtained results were compared with those of pool boiling to consider the contribution of nucleate boiling heat transfer. The results are summarized as follows.

1. A high heat transfer enhancement factor up to 5.2 could be obtained by the thermal spray coating.

2. The heat transfer coefficient increased with increasing liquid flow rate because of the spreading wetting area and then became saturated. The liquid flow rate for the saturation was lower for the coated tube than for the smooth tube due to the spreading easily through the porous structured surface.

3. The hysteresis effect of the heating procedure, as seen in the pool boiling, was observed only for the coated tube. The heat flux decreasing process produced higher heat transfer coefficients due to the retention of the activated nucleation sites.

4. In comparison with the results of pool boiling, for the smooth tube, heat transfer coefficients for falling film evaporation were slightly lower than those for pool boiling, especially in the high heat flux range, because of partial dry out. On the contrary, for the coated tube, the values for falling film evaporation were higher than those for pool boiling due to bubble agitation in the liquid film and increased evaporation from the liquid film surface.

Author Contributions: Conceptualization, T.U., H.A., and K.S.; methodology, K.S. and H.A.; investigation and formal analysis, T.U., H.A., and K.S.; writing—original draft, T.U.; supervision and writing-review and editing, H.A.; project administration, H.A. All authors have read and agreed to the published version of the manuscript.

Funding: This research received no external funding.

Acknowledgments: The authors are indebted to TOCALO Co., Ltd. for processing the thermal spray coating.

Conflicts of Interest: The authors declare no conflict of interest.

\section{References}

1. Fernández-Seara, J.; Pardiñas, Á.Á. Refrigerant falling film evaporation review: Description, fluid dynamics and heat transfer. Appl. Therm. Eng. 2014, 64, 155-171. [CrossRef]

2. Ribatski, G.; Thome, J.R. Experimental study on the onset of local dryout in an evaporating falling film on horizontal plain tubes. Exp. Therm. Fluid Sci. 2007, 31, 483-493. [CrossRef]

3. Christians, M.; Thome, J.R. Falling film evaporation on enhanced tubes, part 1: Experimental results for pool boiling, onset-of-dryout and falling film evaporation. Int. J. Refrig. 2012, 35, 300-312. [CrossRef]

4. Chang, T.B.; Chiou, J.S. Spray evaporation heat transfer of R-141b on a horizontal tube bundle. Int. J. Heat Mass Transf. 1999, 42, 1467-1478. [CrossRef]

5. Chien, L.H.; Tsai, Y.L. An experimental study of pool boiling and falling film vaporization on horizontal tubes in R-245fa. Appl. Therm. Eng. 2011, 31, 4044-4054. [CrossRef]

6. Zheng, Y.; Ma, X.; Li, Y.; Jiang, R.; Wang, K.; Lan, Z.; Liang, Q. Experimental study of falling film evaporation heat transfer on superhydrophilic horizontal-tubes at low spray density. Appl. Therm. Eng. 2017, 111, 1548-1556. [CrossRef]

7. Zhao, C.Y.; Ji, W.T.; Jin, P.H.; Tao, W.Q. Heat transfer correlation of the falling film evaporation on a single horizontal smooth tube. Appl. Therm. Eng. 2016, 103, 177-186. [CrossRef]

8. Jige, D.; Miyata, H.; Inoue, N. Falling film evaporation of R1234ze(E) and R245fa on a horizontal smooth tube. Exp. Therm. Fluid Sci. 2019, 105, 58-66. [CrossRef] 
9. McHale, J.P.; Garimella, S.V. Nucleate boiling from smooth and rough surfaces-Part 1: Fabrication and characterization of an optically transparent heater-sensor substrate with controlled surface roughness. Exp. Therm. Fluid Sci. 2013, 44, 456-467. [CrossRef]

10. Bock, B.D.; Meyer, J.P.; Thome, J.R. Falling film boiling and pool boiling on plain circular tubes: Influence of surface roughness, surface material and saturation temperature on heat transfer and dryout. Exp. Therm. Fluid Sci. 2019, 109, 109-870. [CrossRef]

11. Tehver, J.; Sui, H.; Temkina, V. Heat transfer and hysteresis phenomena in boiling on porous plasma-sprayed surface. Exp. Therm. Fluid Sci. 1992, 5, 714-727. [CrossRef]

12. Asano, H.; Akita, K.; Inoue, M. Effect of gravity on pool boiling heat transfer on thermal spray coating. Microgravity Sci. Technol. 2007, 19, 90-92. [CrossRef]

13. Dewangan, A.K.; Kumar, A.; Kumar, R. Experimental study of nucleate boiling heat transfer of R-134a and R-600a on thermal spray coating surfaces. Int. J. Therm. Sci. 2016, 110, 304-313. [CrossRef]

14. Bogan, N.; Park, C. Influences of solution subcooling, wall superheat and porous-layer coating on heat transfer in a horizontal-tube, falling-film heat exchanger. Int. J. Heat Mass Transf. 2014, 68, 141-150. [CrossRef]

15. Abed, A.M.; Alghoul, M.A.; Yazdi, M.H.; Al-Shamani, A.N.; Sopian, K. The role of enhancement techniques on heat and mass transfer characteristics of shell and tube spray evaporator: A detailed review. Appl. Therm. Eng. 2015, 75, 923-940. [CrossRef]

16. Lemmon, E.W.; Bell, I.H.; Huber, M.L.; McLinden, M.O. NIST Standard Reference Database 23: Reference Fluid Thermodynamic and Transport Properties-REFPROP, Ver. 10.0; National Institute of Standards and Technology: Gaithersburg, MD, USA, 2018.

17. Cooper, M.G. Heat Flow Rates in Saturated Nucleate Pool Boiling-A Wide-Ranging Examination Using Reduced Properties. Adv. Heat Transf. 1984, 16, 157-239. [CrossRef]

(C) 2020 by the authors. Licensee MDPI, Basel, Switzerland. This article is an open access article distributed under the terms and conditions of the Creative Commons Attribution (CC BY) license (http://creativecommons.org/licenses/by/4.0/). 